\title{
Recovery from Lesion-Associated Learning Deficits by Fetal Amygdala Transplants
}

\author{
Suman Jain, Rashmi Mathur, Ratna Sharma and Usha Nayar ${ }^{1}$ \\ Department of Physiology, All India Institute of Medical Sciences, \\ Ansari Nagar, New Delhi, India; \\ ${ }^{1}$ Department of Physiology, College of Medicine and Medical Sciences \\ Arabian Gulf University, P.O.Box 22979, Manama, Bahrain
}

\section{SUMMARY}

Bilateral lesions of the amygdaloid complex result in elimination or attenuation of the conditioned freezing that is normally seen in the conditioned emotional response (CER) paradigm and the active avoidance (AA) task. We observed the effect of amygdalar tissue transplantation on the ability of lesioned (central nucleus of amygdala, $\mathrm{CeA}$ ) rats to learn CER and AA. In two groups of adult Wistar rats, sham operation or bilateral lesions of the $\mathrm{CeA}$ were produced electrolytically ( $2 \mathrm{~mA}$ for $8 \mathrm{sec})$. In a third group, fetal amygdalar tissue was transplanted at the CeA-lesioned site 2 d postoperatively. All rats were trained on CER and AA from the $6^{\text {th }}$ postoperative day. In comparison with the shamoperated group, bilaterally CeA-lesioned rats showed a significant $(p<0.001)$ increase in all CER scores, indicating an acquisition deficit. After fetal amygdalar tissue transplantation, the CER scores significantly decreased $(p<0.05)$ when compared with the lesioned group. A significant $(p<0.01)$ decrease in the percentage of avoidance in the $A A$ task occurring after CeA lesion returned to control values after amygdalar tissue transplantation. In conclusion,

Reprint requests to: Dr. Ratna Sharma, Dept. of Physiology, All India Institute of Medical Sciences, Ansari Nagar, New Delhi-11002․, India; e-mail: sumanjain10@hotmail.com in CeA-lesioned rats a complete behavioral deficit in learning CER and AA was restored by transplanting fetal amygdalar tissue at the lesioned site.

\section{KEYWORDS}

central nucleus of amygdala, conditioned emotional response, active avoidance, amygdalar lesion, neural tissue transplantation

\section{INTRODUCTION}

The central nucleus and the basolateral complex in the amygdala are extensively implicated in learning and memory (Aggleton, 1994). Weiskrantz (1956) first suggested that the effect of amygdalectomy is to make the reinforcement of stimuli, whether positive or negative, difficult to become established or to be recognized as such. Later, Gaffan and Harrison (1987) and then Gaffan (1992) depicted that the tasks impaired by amygdala lesions are those involved in multiple associations between a previously neutral and a primary reinforcing stimulus. Lesions of the central nucleus of the amygdala (CeA) block the expression of several conditioned fear responses, including conditioned emotional response (CER), shock sensitization, and 
fear-potentiated startle (Furmark et al., 1997; Hitchkock \& Davis, 1986; Vazdarjanova \& McGaugh. 1999; Young \& Leaton, 1996). Lesions of the CeA also eliminate or attenuate conditioned freezing, normally seen in response to a stimulus formerly paired with shock (Blanchard \& Blanchard, 1972; LeDoux et al., 1988) or in continuous active and passive avoidance tasks (Slotnick, 1973). In 1989, Ermakova and coworkers attempted to restore such functions in amygdalar-lesioned rats by transplanting fetal amygdalar tissue. Although histologically the transplants were healthy and well integrated with the host, there was no recovery in the acquisition and reacquisition of the aversively motivated 8-arm radial water-maze task. The authors also demonstrated that transplanting cultured cerebellar tissue, rich in the inhibitory mediators GABA and taurine, normalized emotionality and spatial memory in rats without improving the disturbed motor activity, whereas transplanting striatum (Ermakova \& Zhulin, 1996) normalized emotional behavior as well as disturbed motor activity. Jain et al. (2000a) demonstrated recovery of nociceptive behavior in rats by amygdalar tissue transplantation at the lesioned site. A pilot study by Jain et al. (2000b) also showed the ability of $\mathrm{CeA}$-lesioned rats to retain the learning of the active avoidance (AA) task following amygdalar transplantation. To date, the ability of lesioned rats to learn conditioned fear tasks after amygdalar tissue transplantation has not yet been reported. Here, we show for the first time the recovery of CER and AA tasks following fetal amygdalar tissue transplantation at the lesioned site.

\section{EXPERIMENTAL}

\section{Animals}

Adult Wistar male and female rats, weighing between 200 and $300 \mathrm{gm}$ each, were housed in separate polypropylene cages in an animal room having a controlled room temperature of $26 \pm 2^{\circ} \mathrm{C}$ and continuous illumination from 05:00 to 19:00 h. Food and water were available ad libitum except on the days of experiment (as mentioned in later sections when it was). Ethical guidelines as laid down by Indian Council of Medical Research (New Delhi, India) were followed. The rats were divided into the following groups at the beginning of the experiments.

Group I: Control groups: In Group I-a $(\mathrm{n}=5)$, sham operation was performed. Group I-b $(n=5)$ was trained on learning and memory tasks without surgical intervention to study the effect of sham operation.

Group II: CeA lesioned rats $(\mathrm{n}=5)$ : $\mathrm{CeA}$ lesion was produced.

Group III: CeA lesion and transplantation $(\mathrm{n}=10)$ : Fetal amygdalar tissue was transplanted at the $\mathrm{CeA}$ lesioned site $2 \mathrm{~d}$ after lesioning.

From the $6^{\text {th }}$ postlesion day onward, all rats were trained on CER and AA.

\section{Surgery}

On the day of the surgery, the rats were anesthetized with ketamine $(75 \mathrm{mg} / \mathrm{kg}$, i.p.), and a small hole was drilled on either side of the skull, after fixing the head in the stereotaxy, corresponding to CeA (AP 2.3mm, ML 4mm, DV 8mm) (Paxinos \& Watson, 1982). An electrolytic lesion was produced bilaterally by passing direct current $(2 \mathrm{~mA})$ for 8 sec, using bipolar concentric steel electrodes (tip diameter $100 \mu \mathrm{m})$. In the sham-operated rats, the electrode was lowered to the $\mathrm{CeA}$ and then removed without passing current. After surgery, all rats received gentamycin $(8 \mathrm{mg} / \mathrm{kg}$ i.p., twice daily) for 5 days. Rectal temperature and general condition was monitored continuously.

Fetal tissue was obtained from the ketamine $(75 \mathrm{mg} / \mathrm{kg}$, i.m.) anesthetised pregnant (gestation $\mathrm{d}$ 
16) rat for transplantation. The uterus was incised and one viable fetus was separated at a time. The brain of the fetus was removed quickly and placed into chilled sterile lactated Ringer's solution. The amygdala was separated from the cerebral hemispheres and the hindbrain and also made free from any meningeal membranes or choroid plexsus attached to it (Das et al., 1979). The amygdala was dissected from the ventral brain at the level of the median eminence. Two saggital cuts, $1 \mathrm{~mm}$ apart were given approximately $2 \mathrm{~mm}$ lateral to the midline and two horizontal cuts ( $2 \mathrm{~mm}$ apart) were made $1 \mathrm{~mm}$ above from the base of the brain. Approximately $2 \mu \mathrm{l}$ of fetal amygdalar tissue was withdrawn into a glass capillary (inner diameter $0.6 \mathrm{~mm}$ ) fixed to a tuberculin syringe and stereotaxically injected ( $2 \mathrm{~d}$ after producing lesion) into the previously lesioned site. The capillary was left in the same place for $5 \mathrm{~min}$ to prevent backflow of the tissue and then removed gradually.

The study was terminated after the rats had run on all the sessions of CER and AA. At the end of the study, the rats were sacrificed by sedating them with ether and perfusing the aorta with $10 \%$ buffered formalin. The brain was removed and stored in formaldehyde. Later $10-\mu \mathrm{m}$-thick coronal sections were cut and either stained with cresyl violet (for verification of the transplant) or with hematoxylin -eosin (for verification of the lesion).

\section{Behavioral tests}

Conditioned emotional response (CER): The procedure of McIntyre and Molino (1972) was followed for training the rats on CER. To facilitate lever pressing, the rats had access to food for only $1 \mathrm{~h}$ each day. Initially the rats were magazinetrained to press the lever and get the food reward. Each CER session lasted for $10 \mathrm{~min}$. During the first minute, the rat was allowed to explore and get conditioned to the skinner box. After an initial conditioning for $1 \mathrm{~min}$, on the first day of CER training, the rat pressed the lever to get the food for 3 min (block I). During the next 3 min (block II), the buzzer (conditioned stimulus, CS) was presented and the lever-press response was recorded. In block III (next $3 \mathrm{~min}$ ), the rat was again allowed to press the lever uninterruptedly. On the $2^{\text {nd }}$ day, the rats were allowed to press without the buzzer. On the $3^{\text {rd }}$ day, the buzzer was presented again in block II, but it was followed by a foot shock (square wave pulses of $25 \mathrm{~Hz}$ frequency and stimulation strength of $2 \mathrm{~mA}$ for $1 \mathrm{sec}$ ). This schedule of buzzershock pairing was presented on alternate days seven times to circumvent the development of a generalised CER. On the days when the buzzershock was not paired, the rat received only the buzzer. Subsequently from day 15 , the buzzer-shock pairing was presented every day until session 26 .

The suppression ratio (SR, an index of learning) [22] was calculated as the number of lever presses during the block II (B) divided by the number of lever presses during the block I (A) plus the number of lever presses during the block II (B), or $B /(A+B)$. The learning score ( $L S)$ was calculated by taking the mean of the sum of the suppression ratios of all the buzzer-shock paired sessions, beginning from the fourth session. The total learning score is a measure of intensity of the emotional response on all trials. The average score (AS) was calculated by taking the mean of the sum of the suppression ratios of all the non-shock sessions. The suppression score (SS) was the average of the sum of the suppression ratios of the last 10 buzzer-shock paired sessions. All scores were calculated for each rat.

Active avoidance: The procedure reported by Ueki et al. (1994) was used in the present study to train the rats on the AA task. On the 1st day of the experiment, the rat was allowed to explore the box for $5 \mathrm{~min}$. The door was then lowered with the rat in the unsafe compartment (C2). After $20 \mathrm{sec}$, the light and buzzer (conditioned stimulus, CS) was switched on in the $\mathrm{C} 2$, and the door between the 
safe and unsafe compartments was raised. Five seconds later, the rats received a footshock (unconditioned stimulus, US) in the unsafe compartment, either for a maximum of $10 \mathrm{sec}$ or until the rat escaped to the safe compartment $(\mathrm{C} 1)$. If the rat crossed to the safe compartment during the conditioned stimulus, an avoidance response was recorded, otherwise no response was recorded. After an intertrial interval of $45 \mathrm{sec}$, the rat was shifted to the unsafe (C2) compartment and the session was repeated. On alternate days, the rats were given 50 trials. In each session, 50 trials were divided into 5 blocks of 10 trials each. In each block, the number of times the rat avoided the shock was calculated as the percentage of avoidance (POA).

\section{Statistical analysis}

The suppression ratio (SR), learning score (LR), suppression score (SS), average score (AS), and the percentage of POA were calculated for each rat, as described above. To study the pattern of learning in CER, we compared the suppression ratio of the 'only buzzer' sessions of a group amongst themselves using the Freedman test. Later using Kruskal Wallis test, the SR of 'only buzzer' sessions amongst groups I, II, and III were compared. To determine the significant difference amongst groups I, II, and III, of different scores (LS, AS, SS, and POA), Kruskal Wallis, and Multiple range tests were done.

\section{RESULTS}

On histological examination, in all lesioned rats, an electrolytic lesion was observed bilaterally in the central nucleus of amygdala (Fig. 1). Fetal amygdalar tissue (viable neurons, glial cells, ghost cells) was observed bilaterally in CeA in 7 of 10 transplanted rats. In the remaining three rats, it was observed bilaterally in the caudate/putamen. The results of all rats were analyzed extensively, keeping in mind the size and site of the lesion/transplant, but no significant difference was observed.

\section{Conditioned emotional response paradigm}

The suppression ratio was calculated as the ratio of the number of lever presses recorded during block II divided by the number of lever presses recorded during the block I and block II. Thus, if the lever pressing was discontinued or suppressed during the buzzer presentation, the SR would decrease to zero, whereas, if the lever pressing was unaffected by training procedure, it would be 0.5 .

Effect of bilateral CeA lesion on CER: Shamoperation did not affect the learning of CER. No significant difference between the learning score (LS), suppression score (SS), and the respective average score (AS) of sham-operated $(0.12 \pm 0.1$, $0.13 \pm 0.05,0.19 \pm 0.1)$ and unoperated rats $(0.17 \pm 0.1,0.15 \pm 0.1,0.22 \pm 0.14)$ were observed when analyzed using the Kruskal Wallis test. During training in the 'only buzzer' sessions (sessions $1,4,6,8,10,12,14$ ), the suppression ratio (SR) of each session gradually decreased $(p=$ 0.0178 , Freedman test) in sham-operated rats. In the first session, the SR was $0.44 \pm 0.1$ and in the $14^{\text {th }}$ session it was $0.1 \pm 0.1(\mathrm{p}<0.01)$, indicating a gradual learning by the sham-operated rats of the association between the buzzer and the impending shock in CER. In CeA-lesioned rats, a gradual decrement did not occur. In the first session of the CeA-lesioned rats, the suppression ratio was $0.54 \pm$ 0.07 , whereas it was $0.5 \pm 0.04$ in the $14^{\text {th }}$ session $(p=0.337)$. The LS, SS, and AS were also significantly higher $(p=0.0016, p=0.0002, p=0.000$, respectively) (Table 1) in the CeA lesioned rats, when compared with sham-operated rats, indicating an inability of the $\mathrm{CeA}$ lesioned rats to learn conditioned emotional response. 

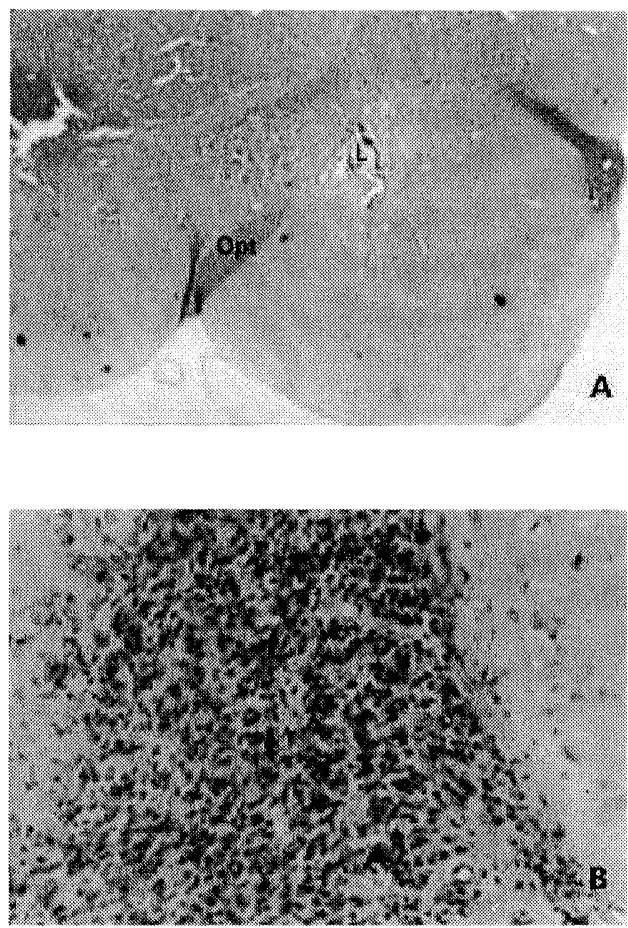

Fig. 1: Photomicrograph of the hematoxylin-eosin and cresyl violet stained stained brain sections of a rat showing electrolytic lesion (A) transplant tissue (B)at the level of central nucleus of amygdala, respectively. Opt is optic tract, $\mathrm{L}$ is the site of lesion and $\mathrm{T}$ is the transplanted tissue.

TABLE 1

Comparison of Learning score, Average score and Suppression score amongst groups I to III.

\begin{tabular}{|l|c|c|c|c|}
\hline Groups & $\mathrm{n}$ & $\begin{array}{c}\text { Learning score } \\
(\text { mean } \pm \mathrm{SD})\end{array}$ & $\begin{array}{c}\text { Average score } \\
(\text { mean } \pm \mathrm{SD})\end{array}$ & $\begin{array}{c}\text { Suppression score } \\
(\mathrm{mean} \pm \mathrm{SD})\end{array}$ \\
\hline Sham op & 5 & $0.12 \pm 0.1$ & $0.19 \pm 0.1$ & $0.13 \pm 0.05$ \\
\hline Lesion & 5 & $0.48 \pm 0.05^{* * *}$ & $0.51 \pm 0.02^{* * *}$ & $0.48 \pm 0.02^{* * *}$ \\
\hline Lesion-transplant & 7 & $0.43 \pm 0.03^{* * * \bullet \bullet \bullet}$ & $0.45 \pm 0.04^{* * *}$ & $0.44 \pm 0.01^{* * * \bullet \bullet}$ \\
\hline
\end{tabular}

* comparison of groups II and III with group I; ${ }^{* * *} \mathrm{p}<0.001 ;{ }^{* *} \mathrm{p}<0.01$;

$\bullet$ comparison of group III with group II, $\bullet \bullet \bullet p<0.001, \bullet \bullet p<0.01$ 
Effect of amygdalar tissue transplant on CER in lesioned rats. In the $\mathrm{CeA}$ lesion-transplanted group, LS and SS respectively significantly decreased to $0.43 \pm 0.03(p=0.0001)$ and $0.44 \pm 0.01(p=0.0031)$ (Table 1) in comparison with the corresponding lesioned group $(0.48 \pm 0.05,0.48 \pm 0.02)$. During training, the suppression ratio in the 'only buzzer' sessions, decreased gradually from $0.52 \pm 0.09$ (in session 1) to $0.38 \pm 0.1$ (in session $14, p=0.055$, Freedman test) in the transplanted rats. This result is in contrast to that in CeA lesioned rats but akin to the pattern of learning in the sham-operated rats. The results indicate a gradual learning of the association between the buzzer and the impending shock by the CeA lesion-transplanted rats. All scores, however, were still higher $(p<0.001$, Kruskal Wallis test) when compared with shamoperated control rats (Table 1), indicating partial recovery of $\mathrm{CeA}$ lesion-transplanted rats from the acquisition deficit. In the three rats in whom bilateral fetal amygdalar tissue was observed in caudate/putamen (time matched controls), LS, SS, and AS were $0.52 \pm 0.2, \quad 0.55 \pm 0.28$, and $0.71 \pm 0.1$ respectively. The observation that these scores were higher than those observed in $\mathrm{CeA}$ lesion-transplanted rats indicated persistence of the acquisition deficit.

\section{Active avoidance task}

Effect of bilateral CeA lesion: The POA was not affected by the sham-operation. In both shamoperated and unoperated rats, the POA increased gradually from block 1 to 5 of the first session. $90 \%$ to $100 \%$ avoidance was achieved during either the $4^{\text {th }}$ or $5^{\text {th }}$ block in the first session itself. During the second and third sessions, about $90 \%$ to $100 \%$ avoidance was maintained (Fig 2a), indicating that the sham-operated rats were able to learn the association between the buzzer and the impending shock from the first session itself. The learning of this information was then retained in subsequent sessions by the sham-operated rats. In bilaterally CeA-lesioned rats, a significant decrease ( $p<0.001$, Multiple Range test) in the percentage of avoidance POA was observed, when compared with sham-operated rats. A maximum of about $40 \%$ of POA was attained in the first session and about $60 \%$ in subsequent sessions (Fig $2 b$ ). This result indicates inability of the CeA-lesioned rats to acquire the AA task.

Effect of amygdalar tissue transplantation: Fetal amygdalar tissue transplantation in the CeAlesioned rats restored the POA to about $80 \%$ to $90 \%$ in the $4^{\text {th }}$ or $5^{\text {th }}$ block of the first session itself. In subsequent sessions, about $100 \%$ avoidance was achieved (Fig 2c); akin to the pattern of learning in sham-operated rats. No significant difference was found between the POA of sham-operated and that of CeA-lesion-transplanted rats. When compared with the CeA lesioned rats, however, a significant $(p<0.001$, Multiple range test) increase occurred in the POA of lesion-transplanted rats, indicating the facilitation of learning the task by the fetal amygdala transplantation. In the three transplanted rats where transplant tissue was observed in caudate/putamen, the POA was about $20 \%$ in the $5^{\text {th }}$ block of first session and $40 \%$ to $50 \%$ in subsequent sessions, indicating no recovery.

\section{DISCUSSION}

The results of the present study have demonstrated that the transplantation of fetal amygdalar tissue in bilateral CeA-lesioned rats leads to an almost complete recovery of the active avoidance (AA) task and to a partial recovery of the conditioned emotional response (CER). The deficit in learning the AA and CER tasks shown by CeA-lesioned rats in this study is in accordance with reports in the literature. As early as 1963 and later, several workers (Kellicut \& Schwartzbaum, 1963; Hitchkock \& Davis, 1986; LaBar et al., 

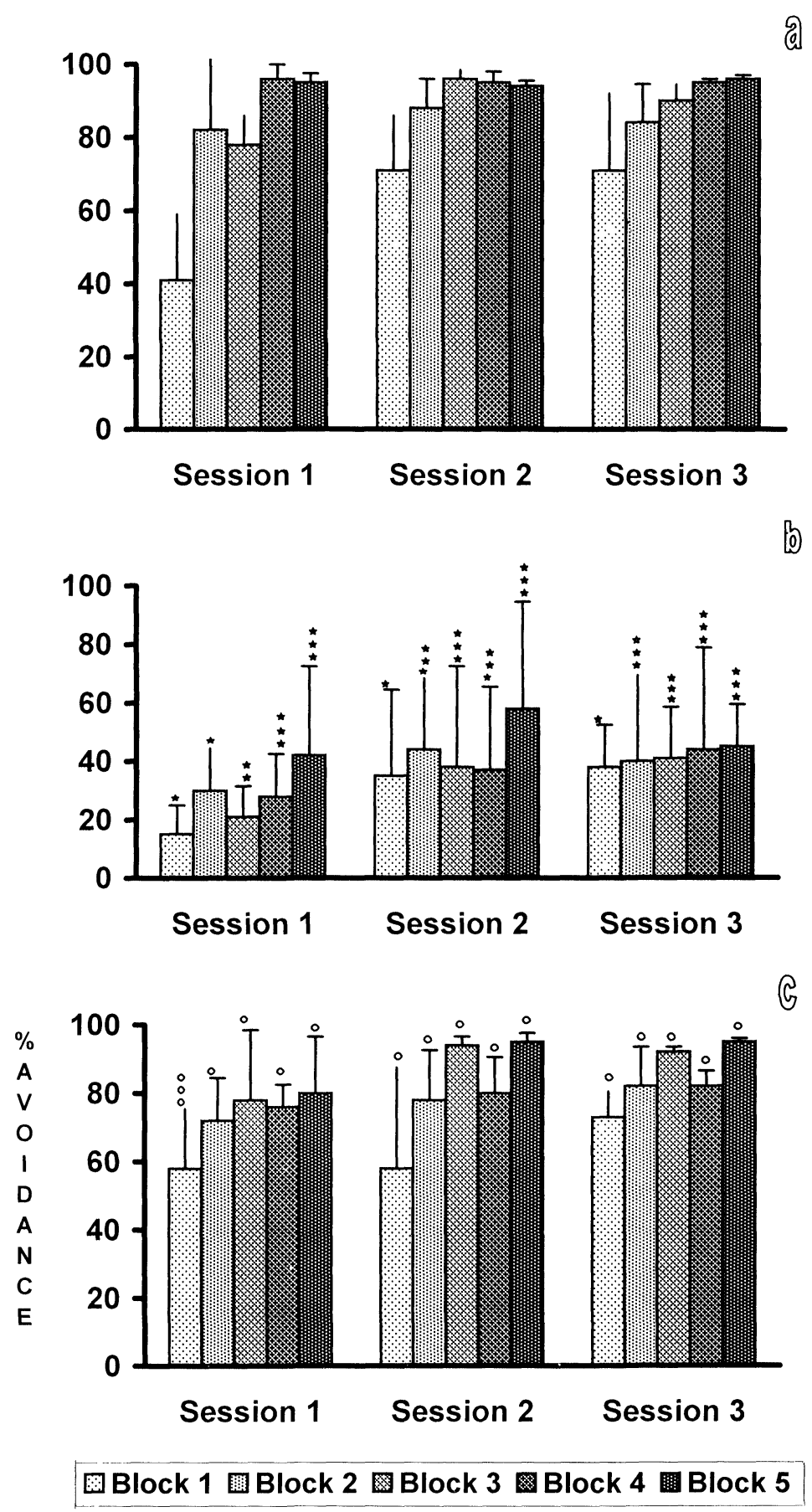

Fig. 2: Effect of sham operation (a), CeA lesion (b) and CeA lesion-transplant (c) on the percentage of avoidance (Mean \pm S.D.) in the three sessions given on alternate days. The POA in each block of group III is compared with the corresponding block of groups II and I and that of group II is compared with group I. * indicates comparison of POA of groups II and III with group I, $* * * \mathrm{p}<0.001, * * \mathrm{p}<0.01, * \mathrm{p}<0.05$. $\bullet$ indicates comparison of POA of group III with group II, $\bullet \bullet p<0.001, \bullet \bullet<0.01, \bullet p<0.05$. The intergroup comparisons were made by using Kruskal Wallis and Multiple Range tests. 
1998) reported an impaired formation of CER following lesions of the whole amygdaloid complex. Kim and Davis (1993) observed retention as well as acquisition deficit in the expression of fearpotentiated startle, a pure index of conditioned fear, following lesion of the CeA. Coleman-Mesches and McGaugh (1995) reported acquisition, retention, and reacquisition deficits $48 \mathrm{~h}$ following bilateral infusions of lidocaine into the $\mathrm{CeA}$, whereas unilateral infusions had no effect on the acquisition deficit. Takashina et al. (1995) reported that amygdaloid lesion in mice resulted in an acquisition deficit in the passive and active avoidance tasks, but not in the spatial learning tasks, indicating the involvement of amygdala in the formation of inhibitory avoidance paradigm. Mesulam and Mufson (1982) suggested that the amygdala is well placed anatomically for such stimulus reinforcement associative learning, for it receives highly processed information about reinforcement from different parts of the cortex. Moreover, by the virtue of extensive processing within different nuclei of amygdala, the sensory information acquires speciesspecific or emotional significance, which is then directed to other brain regions for the marshalling of appropriate behavioral responses (Morris et al., 1999; Pitkanen et al., 1995). Hence, the lesions of CeA result in the loss of innate or conditioned fear (Kemble et al., 1990; LeDoux, 1994; Vazdarjanova \& McGaugh, 1999).

In 1989, Ermakova et al. first made an unsuccessful attempt to restore the 8-arm watermaze task by transplanting amygdalar tissue at the lesioned site. Later, they successfully obtained the recovery of emotionality and motor activity, respectively, (Ermakova \& Zhulin, 1996), by transplanting cerebellum or striatum at the lesioned site. In the present study, we observed that when the grafts were in the caudate/putamen, no recovery took place. On the other hand, when the grafts were in central nucleus of amygdala, recovery of CER and AA did occur. Although this finding might have to be confirmed in a large group of animals, possibly for embryonic grafts to be effective-whether of amygdala or cerebellum origin or from any other tissue, as reported by Ermakova and Zhulin (1996) - it is essential that they should be transplanted in the area of the lesion, but not nearby.

The present study found a partial recovery of CER and a complete recovery of AA tasks after fetal amygdalar transplantation at the lesioned site. Sprick (1991) also observed a transient amelioration of behavioral deficits in a T-maze alternation task and a long-lasting improvement in the alcove test. The author suggested that the grafts behave in a differential manner, with the neuronal circuits controlling different kinds of behavior, and that the graft effects vary with time.

In the present study, CER and AA also measure different aspects of conditioned fear. The CER is a measure of classical conditioning, for which the amount of suppression of ongoing operant or consummatory behavior is used as an index of the strength of fear, whereas, in the AA task, frequency of avoidance is used for measuring fear. In CER, the animal learns to prepare itself for the impending aversive stimuli, whereas, in AA it learns to avoid.

Sprick (1991) also suggested that the initial recovery in the T-maze task might be due to the release of neurotrophic factors, and the longlasting recovery to the formation of synaptic connections. Gash et al. (1994) and NietoSampedro et al. (1983) reported that titers of trophic factors are maximal after 2 wk of lesion and then gradually decay. This effect can partially explain the complete recovery of the AA task observed in the present study because the test was done between 8 and $15 \mathrm{~d}$ of lesion and partial recovery of the CER $(33 \mathrm{~d})$. On histological confirmation, viable neurons were seen at the site of transplantation, which might have provided an appropriate environment for the formation of 
synaptic connections between the host and the grafted tissue.

Sollars and Pickard (1993) demonstrated that anterior hypothalamic grafts of mouse and rat origin send axons into the surrounding hamster neuropil within $2 \mathrm{~d}$ of implantation into the host's third ventricle, which becomes extensive within 2 wk. Several investigators (Kelche et al., 1974; DalrympleAlford et al., 1988; Kolb et al., 1988) have also suggested that sometimes the graft interferes with the endogenous functional reorganization of the host by forming functionally irrelevant connections to the host brain, and that this effect occurs typically after long post-graft periods. A gradual decrease could take place in the grafted tissue with time, due to general immuno-reactive rejection or individual cell death. Grafted neurons that do not make connections to host targets would probably die, as they do not receive enough retrogradely transported intrinsic growth factors to survive over long periods of time. On histological analysis we did find glial reaction along with viable and ghost neurons at the site of transplantation.

Degeneration of the host tissue has also been shown to stimulate the production of neurotrophic, activating factors and the expression of neuromodulators (Alvarado-Mallart \& Sotelo, 1993; Tomey \& Heckroth, 1993; Heckroth et al., 1998). These factors attenuate the neuronal loss by arresting degeneration of the adult host tissue and by encouraging sprouting of the intact axon (Borlongan et al., 1998). In the present study, the observation that rats with grafts in the caudate/ putamen still showed acquisition deficits of both CER and AA indicates that the recovery observed in rats with amygdalar grafts cannot be attributed to the release of neurotrophic or activating factors by the injured tissue.

The exact mechanism responsible for the recovery of the learning abilities of CeA-lesioned rats is not known. Time-matched controls, rats in which transplant tissue were observed in the caudate/putamen, did not show a similar recovery. Therefore, the results suggest that amygdalar tissue transplants are capable of inducing recovery of conditioned emotional response and active avoidance tasks in CeA-lesioned rats.

\section{ACKNOWLEDGEMENTS}

This study was supported by a research grant from the Indian Council of Medical Research and A.I.I.M.S, New Delhi, India. We are grateful to Mr. Sadhu Ram, Mr. Nathu Ram, and Mr. Purushottam for their technical assistance.

\section{REFERENCES}

Aggletonn JP. 1994. The Amygdala: Neurobiological Aspects of Emotion, Memory and Mental Dysfunction. New York, NY, USA: Willey Liss; 339-352.

Alvarado-Mallart RM, Sotelo C. 1993. Cerebellar grafting in murine heredo degenerative ataxia. Current limitations for a therapeutic approach. Adv Neurol 61: 81.

Blanchard DC, Blanchard RJ. 1972. Innate and conditioned reactions to threat in rats with amygdaloid lesions. J Comp Physiol Psychol 81: 281-290.

Borlongan CV, Tajima Y, Trojanoswski JQ. Transplantation of cryopreserved human embryonal carcinoma derived neurons (NT2N cells) promotes functional recovery in ischemic rats. Exp Neurol 1998. 149: 310-321.

Coleman-Mesches K, McGaugh JH. 1995. Differential effects of pretraining inactivation of the right or left amygdala on retention of inhibitory avoidance training. Behav Neurosci 109: 642-647.

Dalrymple-Alford JC, Kelche CR, Cassell JC, Toniolo G, Pallage V, Will B. Behavioral deficits after hippocampal fetal septal grafts in rats with selective fimbria-fornix lesions. Exp Brain Res 1988. 69: 545-558.

Das GD, Hallas BH, Das KG. 1979. Transplantation of neural tissues in the brains of laboratory mammals: 
Technical details and comments. Experentia 35: 143-153.

Ermakova IV, Loseva EV, Valouskova V, Bures J. 1989. The effect of embryonal amygdalar grafts on the impairment of spatial working memory elicited in rats by Kainate induced amygdaloid damage. Physiol Behav 45: 235-241.

Ermakova IV, Zhulin VV. 1996. Recovery of behavioral functions following the transplantation of the embryonal striatum into the damaged amygdala of the rat brain. Neurosci Behav Physiol 26: 11-12.

Furmark T, Fischer H, Wik G, Larsson M, Fredrickson M. 1997. The amygdala and individual differences in human fear conditioning. Neuroreport 8: 3957-3960.

Gaffan D, Harrison S. 1987. Amygdalectomy and disconnection in visual learning for auditory secondary reinforcement by monkeys. J Neurosci 7: 2285-2292.

Gaffan D. 1992. Amygdala and the memory of reward. In: Aggleton JP, ed, The Amygdala: Neurobiological Aspects of Emotion, Memory and Mental Dysfunction. New York, NY, USA: Wiley Liss; 471-484.

Gash DM, Bresjanae M, Junn F, Zhang Z. 1994. Trophic mechanisms mediating functional recovery following intrastriatal implantation. In: Dunnett SB, Bjorklund, eds, Functional Neural Transplantation; 139-156.

Heckroth JA, Hobert NJH, Summer D. 1998. Transplanted neurons alter the course of neurodegenerative disease in Lurcher mutant mice. Exp Neurol 154: 336-352.

Hitchcock JM, Davis M. 1986. Lesions of the amygdala, but not of the cerebellum or red nucleus, block conditioned fear as measured with the potentiated startle paradigm. Behav Neurosci 100: 11-22.

Jain S, Mathur R, Sharma R, Nayar U. 2000a. Amygdalar tissue transplants improve recovery of nociceptive behavior in rats. Restor Neurol Neurosci 16: 143-147.

Jain S, Mathur R, Sharma R, Nayar U. 2000b. Fetal amygdalar transplantation facilitates recovery of retention deficit in $\mathrm{CeA}$ lesioned rats. Ind J Exp Biol 38, 1014-1019.

Kelche C, Dalrymple-Alford JC, Cassel JC, Will BE. 1974. The effect of fetal septal cell transplants in rats with selective fimbria-fornix lesions: a behavioral and histological study. Soc Neurosci Abstr 12.

Kellicut MH, Schwartzbaum JS. 1963. Formation of a conditioned emotional response (CER) following lesions of the amygdaloid complex in rats. Psychol Rev 12: 351-358.

Kemble ED, Blanchard DC, Blanchard RJ. 1990. Effects of regional amygdaloid lesions on flight and defensive behaviors of wild black rats (Rattus rattus). Physiol Behav 48: 1-5.

Kim M, Davis M. 1993. Electrolytic lesions of the amygdala block fear potentiated performance in hippocampal lesioned rats. Behav Neurosci 107: 586-595.

Kolb B, Reynolds B, Fantie BD. 1988. Frontal cortex grafts have opposite effects at different postoperative recovery times. Behav Neural Biol 50: 193-206.

LaBar KS, Gatenby JC, Gore JC, LeDoux JE, Phelps EA. 1988. Human amygdala activation during conditioned fear acquisition and extinction: a mixed trial fMRI study. Neuron 20: 937-994.

Le Doux JE, Iwata J, Cicchetti P, Reis DJ. 1988. Different projections of the central amygdaloid nucleus mediate autonomic and behavioral correlates of conditioned fear. J Neurosci 8: 25172529.

Le Doux JE. 1994. Emotion and the amygdala. In: Aggleton JP, ed, The Amygdala: Neurobiological Aspects of Emotion, Memory and Mental Dysfunction, Wiley Liss, New York; 339-352.

McIntyre DC, Molino A. 1972. Amygdalar lesions and CER learning: Long term effects of kindling. Physiol Behav 8: 1055-1058.

Mesulam MM, Mufson EJ. 1982. Insula of the old world monkey. III Efferent cortical outputs and comments on function. J comp Neurol 212: 38-52.

Morris JS, Ohman A, Dolan RJ. 1999. A subcortical pathway to the right amygdala mediating "unseen fear". Proc Natl Acad Sci USA 96: 1680-1685.

Nieto-Sampedro M, Manthrope M, Barbin G, Varon S, Cotman CW. 1983. Injury induced neuronotrophic activity in adult rat brain: correlation with survival of delayed implants in the wound cavity. J Neurosci 3: 2219-2229.

Paxinos G, Watson C. 1982. The Rat Brain in Stereotaxic Co-ordinates. Sydney, Australia: Academic Press

Pitkanen A, Stenfanacci L, Farb CR, Go GG, LeDoux JE. Amaral DG. 1995. Intrinsic connections of the rat amygdaloid complex: projections originating in the lateral nucleus. J Comp Neurol 356: 288-310.

Slotnick BM. 1973. Fear behavior and passive avoidance deficits in mice with amygdala lesions. Physiol Behav 11: 717-720. 
Sollars PJ, Pickard JE. 1993. Time course of fibre outgrowth from fetal anterior hypothalamic heterografts. Brain Res 614: 212-219.

Sprick U. 1991. Transient and long lasting beneficial behavioral effects of grafts in the damaged hippocampus of rat. Behav Brain Res 42: 187-199.

Takashina K, Saito H, Nishiyama N. 1995. Preferential impairment of avoidance performances in amygdala. Jpn J Pharmacol 67: 107-115.

Tomey DA, Heckroth JA. 1993. Transplantation of normal embryonic cerebellar cell suspensions into the cerebellum of lurcher mutant mice. Exp Neurol 122: 165-170.

Ueki A, Miwa C, Miyoshi KJ. 1994. Impairment in the acquisition of active and passive avoidance learning tasks due to entorhinal cortex lesions. J Neurol Sci 125: 14-21.

Vazdarjanova A, McGaugh JL. 1999. Basolateral amygdala is involved in modulating consolidation of memory for classical fear conditioning. J Neurosci 19: 6615-6622.

Weiskrantz L. 1956. Behavioral changes associated with ablation of the amygdaloid complex in monkeys. J Comp Physiol Psychol 49: 381-391.

Young BJ, Leaton RN. 1996. Amygdala central nucleus lesions attenuate acoustic startle stimulus evoked heart rate changes in rat. Behav Neurosci 110: 228-237. 

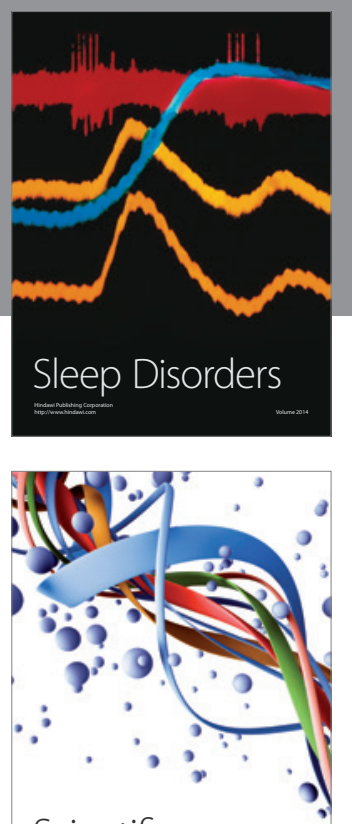

Scientifica
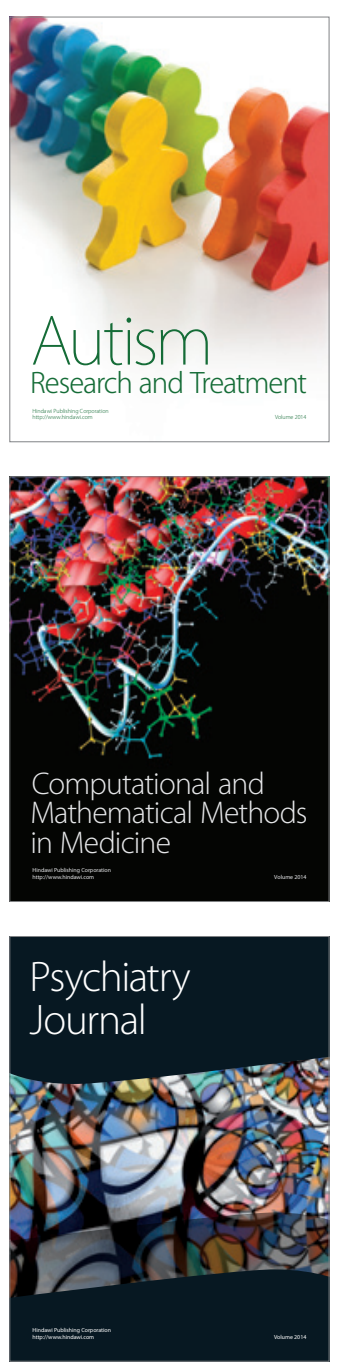
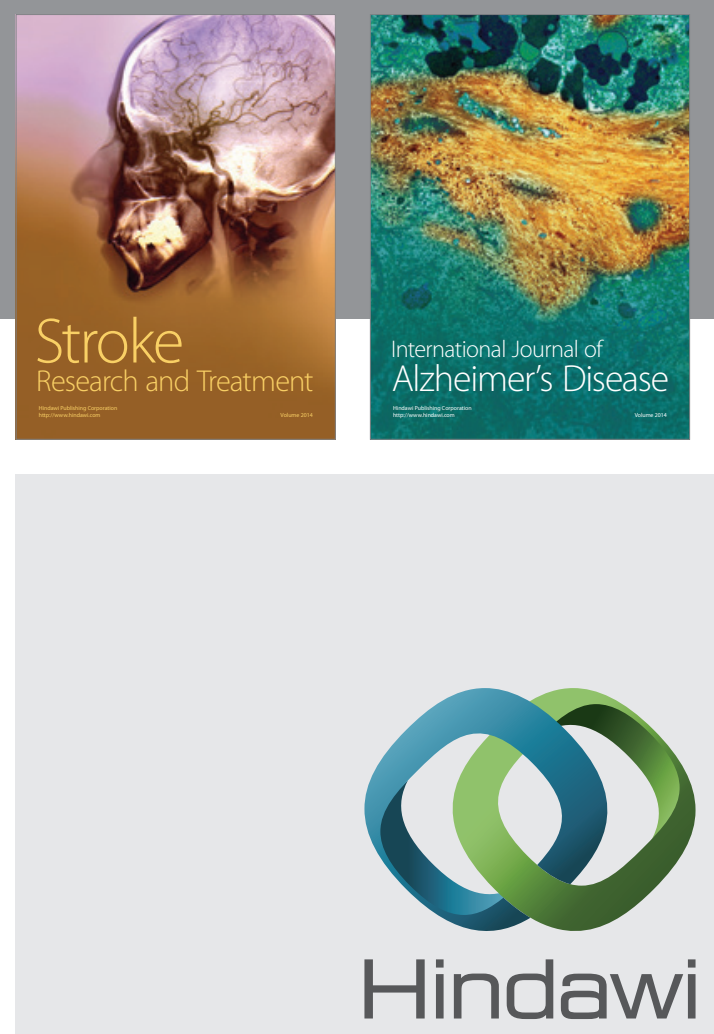

Submit your manuscripts at

http://www.hindawi.com
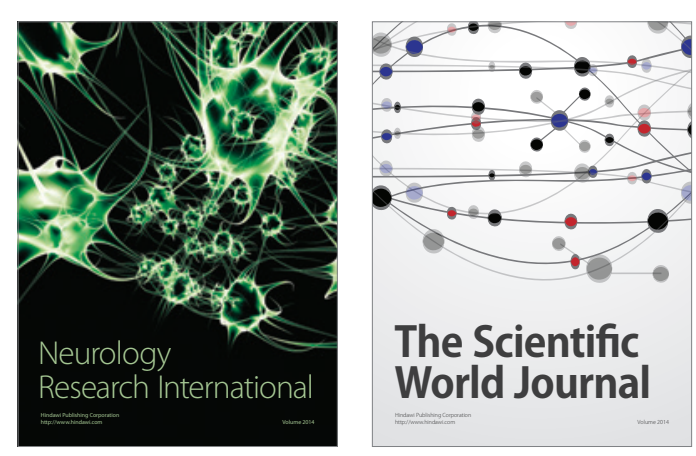

The Scientific World Journal

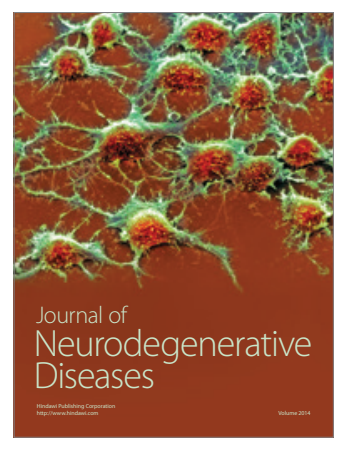

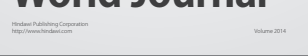

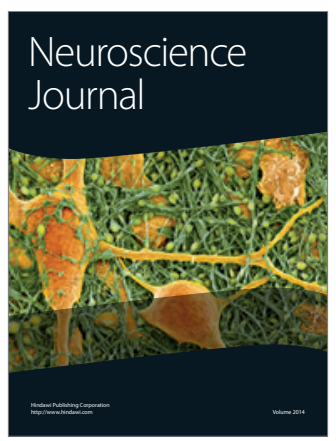

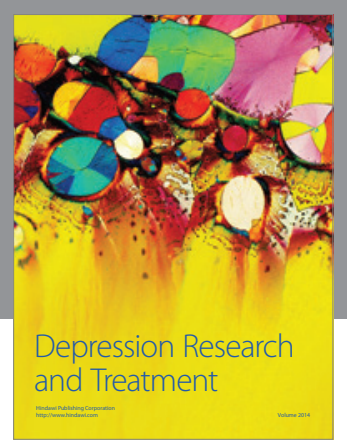
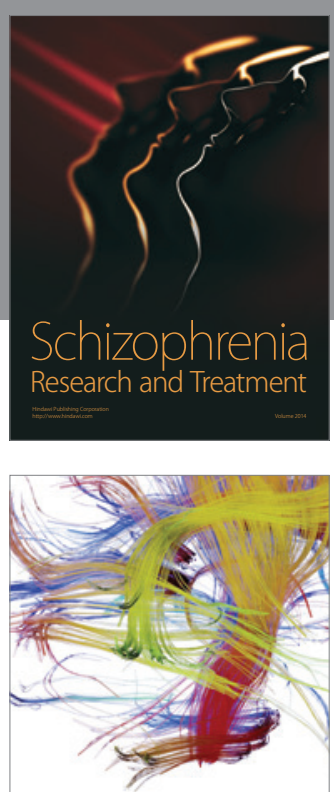

Brain Science

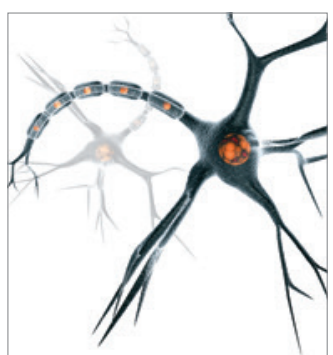

Neural Plasticity
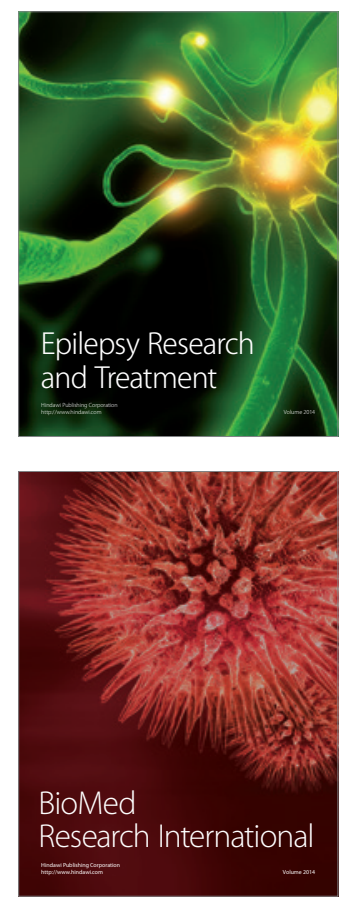

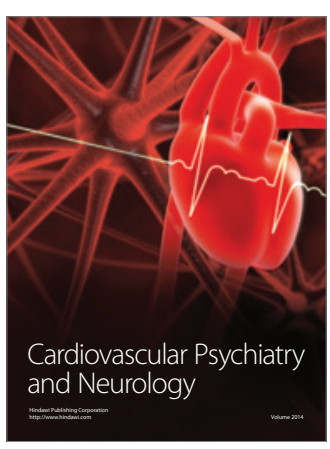

Parkinson's

Disease
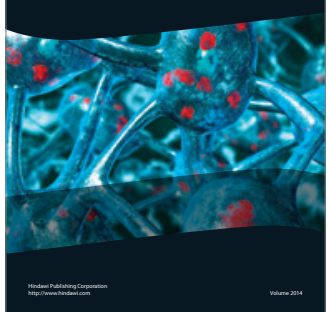